\title{
Influence of door handles design in effort perception: accessibility and usability
}

\author{
Luis Carlos Paschoarelli a, ${ }^{\mathrm{a}}$, Raquel Santos ${ }^{\mathrm{b}}$ and Paula Bruno ${ }^{\mathrm{c}}$ \\ ${ }^{a}$ Design Department, Paulista State University, Av. Eng. Luis E. C. Coube, 14-01, 17033-360, Bauru, Brazil \\ ${ }^{\mathrm{b}}$ Ergonomics Department, Technical University of Lisbon, Estrada da Costa, 1495-688, Cruz Quebrada, Portugal \\ ${ }^{\mathrm{c}}$ Mathematical Methods Department, Technical University of Lisbon, Estrada da Costa, 1495-688, Cruz \\ Quebrada, Portugal
}

\begin{abstract}
The application of ergonomics in product design is essential to its accessibility and usability. The development of manual devices should be based on ergonomic principles. Effort perception analysis is an essential approach to understand the physical and subjective aspects of the interface. The objective of the present study was to analyze the effort perception during a simulated task with different door handles by Portuguese subjects of both genders and different ages. This transversal study agreed with ethical aspects. 180 subjects of both genders pertaining to three age groups have participated. Five door handles with different shapes were evaluated. A subjective numeric rating scale of 5 levels was used to evaluate the effort. For statistical analysis it was applied the Friedman non-parametric test. The results have showed no significant differences of effort perception in door handles "A" and "B"; "A" and "D"; and "D" and "C". Door handle "E" presented the lowest values of all. In general, there's an inverse relationship between the results of biomechanical studies and the effort perception of the same task activity. This shows that door handles design influence directly these two variables and can interfere in the accessibility and usability of these kinds of products.
\end{abstract}

Keywords: ergonomic design, accessibility, usability, door handles.

\section{Introduction}

The application of ergonomics in product design is essential to its accessibility and usability. The development of manual devices should be based on ergonomic principles otherwise during its use there will be constraints and discomfort [3].

The arguments of the accessibility also characterizes the so-called universal design principles, which aim to evaluate existing designs, guide production processes and educate designers and consumers about product features and improved usability environments [9].

Biomechanical studies $[4,5,6,7,8]$ have shown that manual devices design can influence human performance. Meanwhile effort perception analysis is an essential approach to understand the physical and subjective aspects of the interface.
According to Borg [2], subjective evaluations, that complement physiological or biomechanical methods, contribute to the establishment of acceptable workloads.

The objective of the present study was to analyze the effort perception during a simulated task with different door handles by Portuguese subjects of both genders and different ages.

\section{Materials and methods}

This transversal study agreed with ethical aspects [1]. The subjects signed a permission to accomplish the required task for the research.

A sample of 180 subjects of both genders belonging to three age groups - between 18 and 29 years; between 30 and 55 years; and above 55 years (30

\footnotetext{
*Corresponding author. Tel. no. +55 14 31036057. Fax. No. +55 14 31036050. E-mail: paschoarelli@faac.unesp.br.
} 
subjects of each gender in each age group) have participated in this research.

A fixed support was used to place the door handles - at about $950 \mathrm{~mm}$ high - and perform the task simulation. This support was fixed in a metallic base of $700 \times 700 \mathrm{~mm}$, where the subject stands still to per- form the simulated task (Figure 1). The apparatus was completed with a scale and an anthropometer to collect subjects' weight and stature. Five door handles ("A", "B", "C", "D" and "E") with different shapes were evaluated (Figure 2).

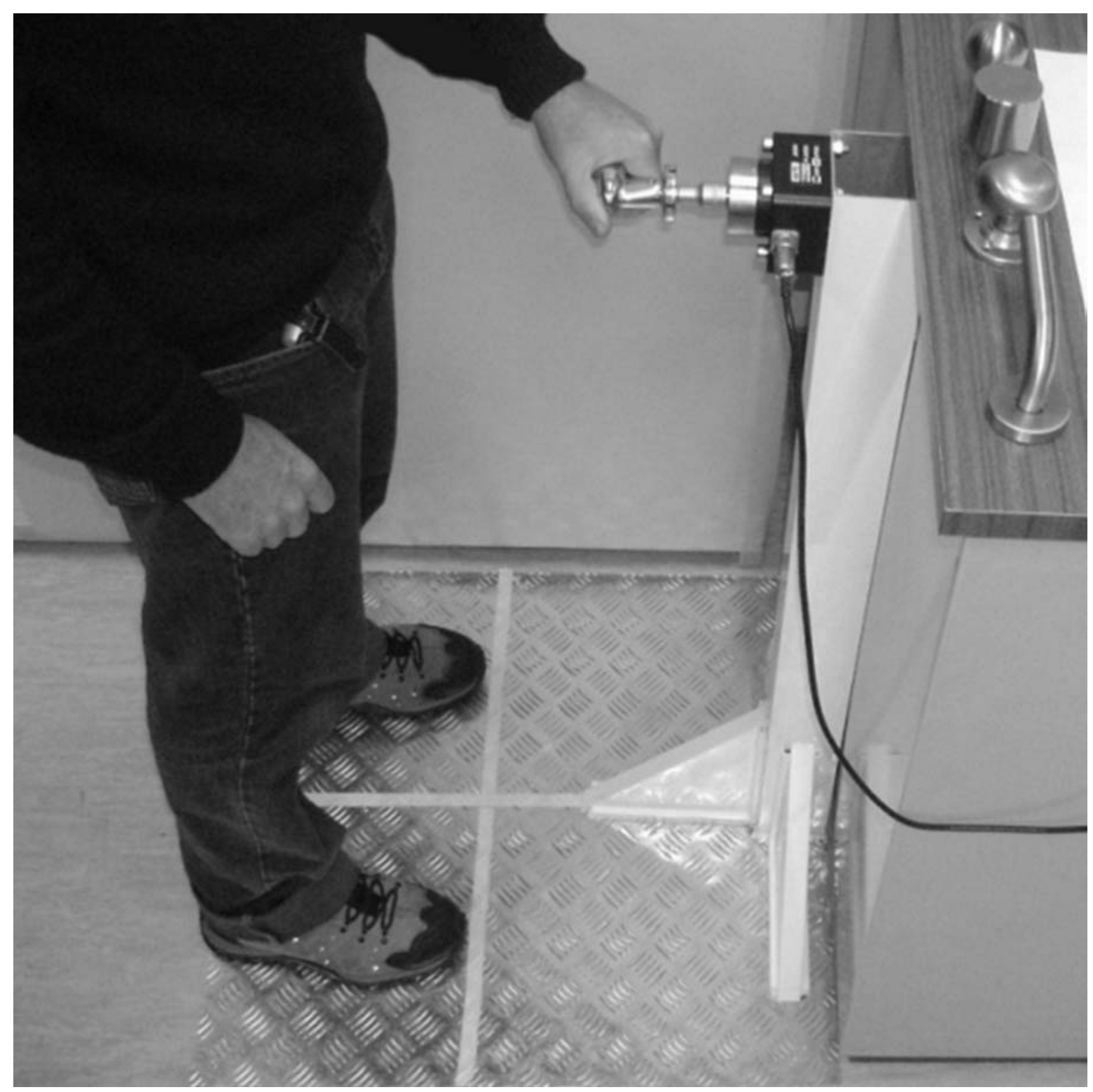

Figure 1. Realization of task simulation in the fixed support used to place the door handles. 

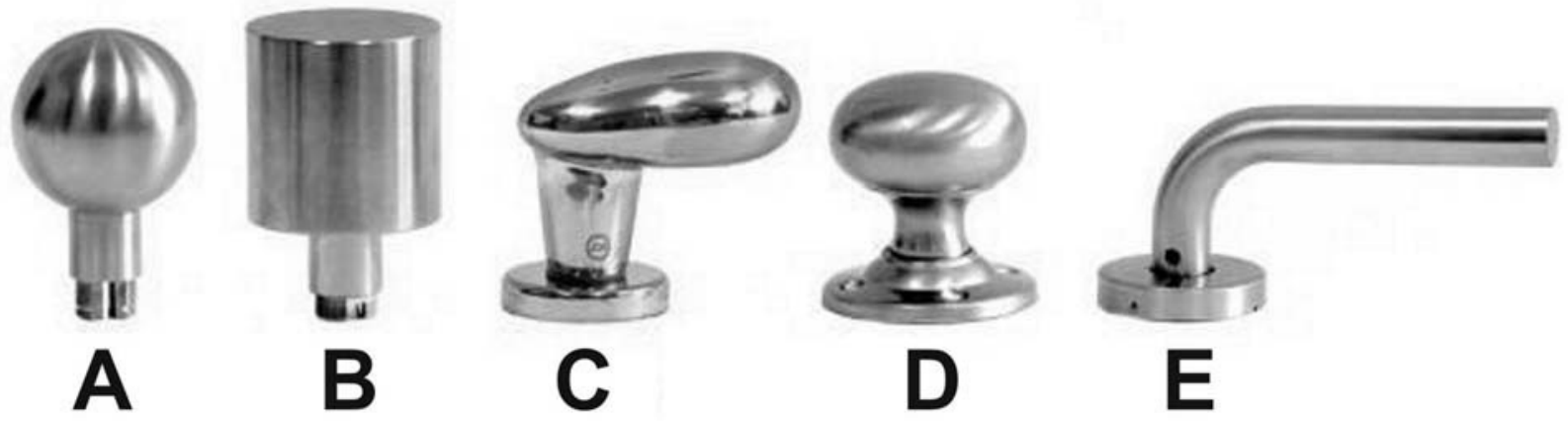

E

Figure 2. Door handles evaluated.

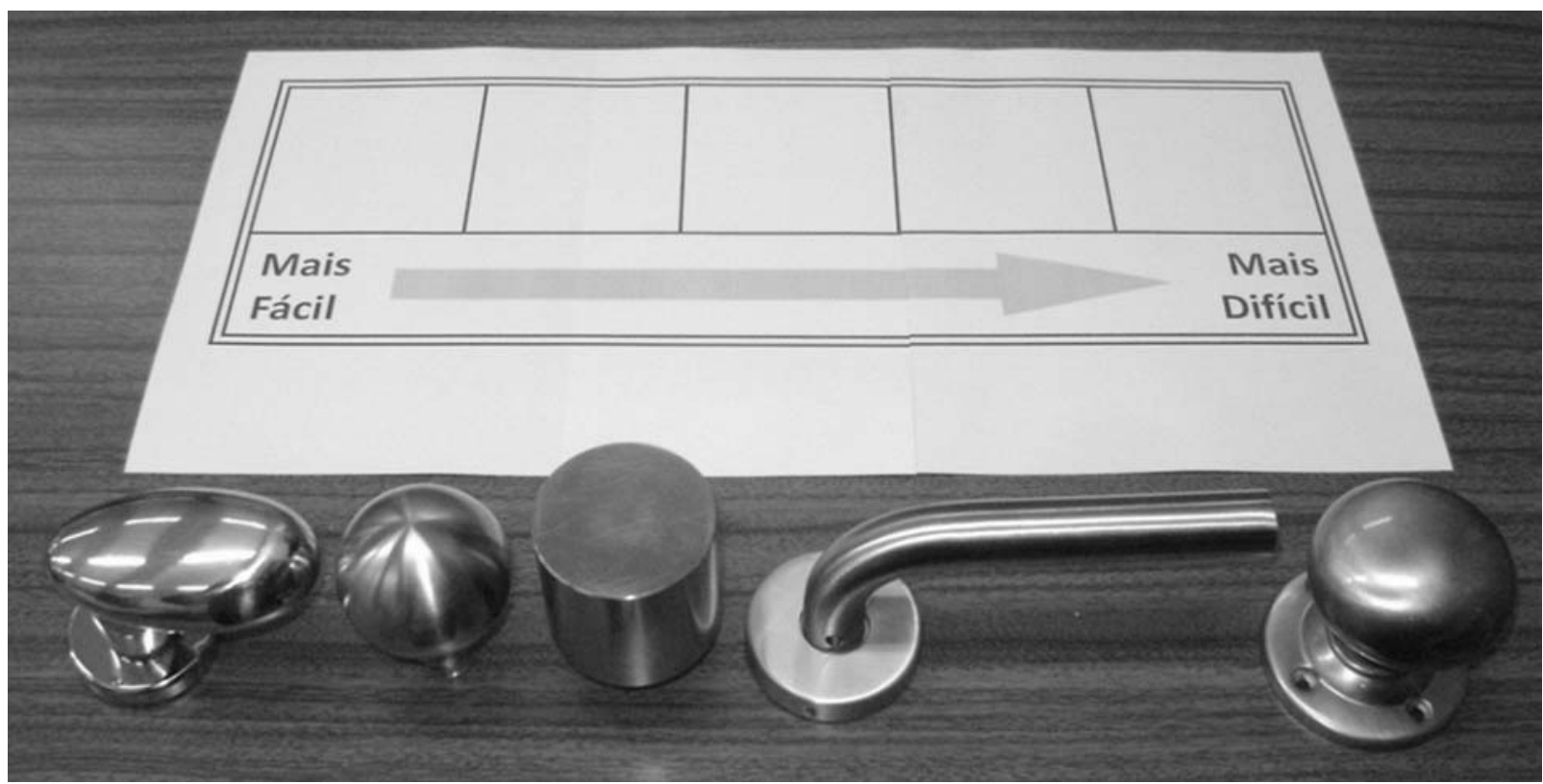

Figure 3. Subjective rating scale (in Portuguese), with the five door handles.

Standardized instructions to perform the simulated task of opening a door handle were presented to the subjects. At the end, to demand the door handles hierarchization regarding the effort needed to perform the task, a subjective rating scale of 5 levels was used to evaluate the effort perception: 1 to "the lower effort" and 5 to "the highest effort" (Figure 3). The door handles were placed randomly for all subjects.

It was applied the Friedman non-parametric test and post-hoc tests described by Zar [10], that allow the identification of which groups presented significant differences.

\section{Results}

The results of the mean values of effort perception to perform the activity with the various door handles, considering the different gender groups and age groups are demonstrated in Figure 4. The indices with higher average values belong to the door handles "A" followed by door handles "B", "D", "C" and "E", with statistically significant differences $(\mathrm{p} \leq$ 0.05 ) between door handles "A" and "E" in all groups, "A" and "C" in groups of male subjects (all ages) and female subjects (18-29 years), "B" and "E" in all groups, and "B" and "D" in groups of male subjects (30-55 years and greater than 55 years). 


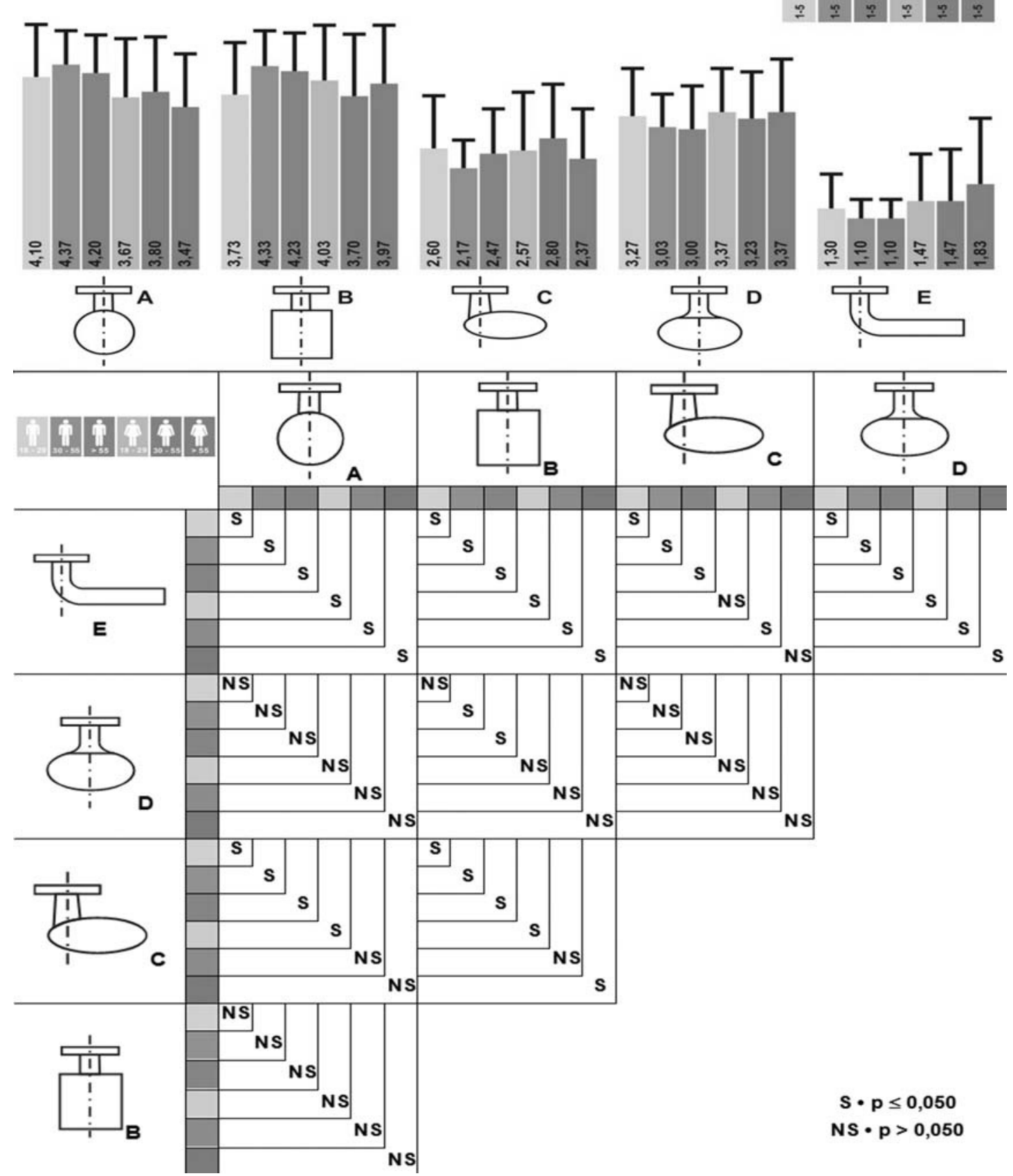

Figure 4. Mean values (and s.d.) of effort perception for different door handles, divided by gender and age (18-29, 30-55, and greater than 55 years).

Below are the significance levels for Friedman non-parametric test and post-hoc tests described by ZAR [10] (p. 267). 
There are still significant differences $(p \leq 0,05)$ between door handles " $\mathrm{B}$ " and " $\mathrm{C}$ " in males of all ages, and females between 18 and 29 and above 55 years; between " $C$ " and " $E$ " in males of all ages and females between 30 and 55 years; and "D" and "E" for all groups and genders.

\section{Discussions and conclusions}

Studies about effort perception of manual devices, especially door handles, are exploratory.

In gender comparison, it is observed that males indicate a higher average rate of effort required to perform the activity in small door handles. This proportion is reversed, with the change of door handle design. In hand door "E", males perceive a significantly lower effort $(p \leq 0,05)$, compared with female.

In the case of age, the results indicate a behavior pattern with no significant differences between age groups for any of the door handles, which demonstrates that perceived exertion is not influenced by age.

Regarding effort perception among different door handles, there weren't significant differences between door handles "A" and "B", "A" and "D" and "D" and "C", and the knob "E" stood out from the others, with lower means of effort perception, compared to most interactions.

In general, there's an inverse relationship between the results of biomechanical studies [7] and the effort perception of the same task activity. This shows that door handles design influence directly these two variables and can interfere in the accessibility and usability of these kinds of products.

\section{Acknowledgements}

This study was supported by CNPQ - National Council for Scientific and Technological Development (Proc. 303138/2010-6); and FAPESP - São Paulo Research Foundation (Proc. 2005/59941-2).

\section{References}

[1] Abergo. ERG BR $1002 . \quad$ In:

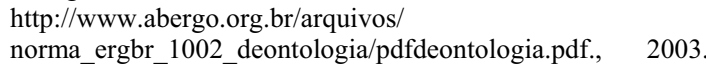
Acessed in December 20, 2004.

[2] Borg, G. Borg's Perceived Exertion and Pain Scales. Champaign: Human Kinetics, 1998.

[3] Cacha, C.A. Ergonomics and safety in hand tool design. New York: Lewis Publishers, 1999.

[4] Cochran, D. J. and Riley, M. W. The effects of handle shape and size on exerted forces. Human Factors 28 (1986): 253-265.

[5] Crawford, J. O., Wanibe, E. and Laxman, N. The interaction between lid diameter, height and shape on wrist torque exertion in younger and older adults. Ergonomics 45 (2002): 922923.

[6] Mital, A. Effect of body posture and common hand tools on peak torque exertion capabilities. Applied Ergonomics, 17 (1986): 87-96.

[7] Paschoarelli, L. C. and Santos, R. Usability evaluation of different door handles, in: Advances in Cognitive Ergonomics, D.B. Kaber and G. Boy, eds., CRC Press, Boca Raton, 2011, pp. 291-299.

[8] Shih, Y. C. and Wang, M. J. J. Hand/tool interface effects on human toques capacity. International Journal of Industrial Ergonomics, 18 (1996): 205-213.

[9] Story, M.F.; Mueller, J.L. and Mace; R.L. The Universal Design File: Designing for people of all ages and abilities. Revised edition. Washington: North Carolina State University - Center for Universal Design, 1998. 170p.

[10]Zar, J. H. Biostatistical Analysis. Upper Saddle River: Prentice Hall, 1999. 